\title{
Extracellular $\alpha$-synuclein alters synaptic transmission in brain neurons by perforating the neuronal plasma membrane
}

Carla R. Pacheco ${ }^{1}$, Camila N. Morales ${ }^{1}$, Alejandra E. Ramírez ${ }^{1}$, Francisco J. Muñoz ${ }^{2}$, Scarlet S. Gallegos ${ }^{1}$, Pablo A. Caviedes ${ }^{3}$, Luis G. Aguayo ${ }^{1 *}$ and Carlos M. Opazo ${ }^{4 *}$.

${ }^{1}$ Department of Physiology, University of Concepcion, P. O. Box 160-C, Concepcion, Chile.

${ }^{2}$ Laboratory of Molecular Physiology and Channelopathies, Universitat Pompeu Fabra, Barcelona, Spain.

${ }^{3}$ Program of Molecular and Clinical Pharmacology, Faculty of Medicine, ICBM, University of Chile, Santiago, Chile.

${ }^{4}$ Oxidation Biology Laboratory, The Florey Institute of Neuroscience and Mental Health, Victoria 3010, Australia

*To whom correspondence should be addressed: Dr. Carlos Opazo, The Florey Institute of Neuroscience \& Mental Health, The University of Melbourne, Melbourne, VIC 3010, Australia. Telephone: 61-3-90359997. E-mail address: carlos.opazo@florey.edu.au; Dr. Luis G. Aguayo, Department of Physiology, University of Concepción. P.O. Box 160-C, Concepción, Chile. Telephone: 56-41-2203380. Fax: 56-41-2245975. e-mail:laguayo@udec.cl

Keywords: $\alpha$-synuclein, Calcium, Parkinson's disease, perforation, pore-like structures.

Running title: Extracellular $\alpha$-synuclein perforates neuronal plasma membrane. 
Abbreviations: $\alpha$-syn, $\alpha$-synuclein; ( $N$-(3-Triethylammoniumpropyl)-4-(4-(Dibutylamino) Styryl) Pyridinium Dibromide), FM1-43; 6-(N-(7-Nitrobenz-2-oxa-1,3-diazol-4-yl)amino)-6Deoxyglucose, 6-NBDG; PD, Parkinson's disease.

\begin{abstract}
It has been postulated that the accumulation of extracellular $\alpha$-synuclein $(\alpha$-syn) might alter the neuronal membrane by formation of "pore-like structures" that will lead to alterations in ionic homeostasis. However, this has never been demonstrated to occur in brain neuronal plasma membranes. In this study, we show that $\alpha$-syn oligomers rapidly associate to hippocampal membranes in a punctate fashion, resulting in increased membrane conductance ( 5 fold over control) and the influx of both calcium and a fluorescent glucose analogue. The enhancement in intracellular calcium (1.7 fold over control) caused a large increase in the frequency of synaptic transmission (2.5 fold over control), calcium transients ( 3 fold over control) and synaptic vesicle release. Both primary hippocampal and dissociated nigral neurons showed rapid increases in membrane conductance by $\alpha$-syn oligomers. In addition, we show here that $\alpha$-syn caused synaptotoxic failure associated to a decrease in SV2, a membrane protein of synaptic vesicles associated to neurotransmitter release. In conclusion, extracellular $\alpha$-syn oligomers facilitates the perforation of the neuronal plasma membrane, thus explaining, in part, the synaptotoxicity observed in neurodegenerative diseases characterized by its extracellular accumulation.
\end{abstract}




\section{Introduction}

Parkinson's disease (PD) is a neurodegenerative disease that affects autonomic, cognitive, motor and sensory brain regions (Braak et al. 2004). Therefore, non-motor symptoms such as dementia are also detected in patients with PD (Aarsland et al. 2007), but this has attracted much lesser attention. It is likely that these alterations in cognitive functions are associated to brain regions such as the hippocampus and cerebral cortex.

PD is classified as an $\alpha$-synucleinopathy because the presence of $\alpha$-syn aggregates in the intracellular inclusion bodies called Lewy bodies (LBs), which are found in the brains of PD patients (Spillantini et al. 1998). $\alpha$-syn is a small unstructured soluble protein of 140 amino acids highly expressed in the brain (Surguchov 2013). Considering that $\alpha$-syn is a cytosolic protein, it has been assumed that the neurotoxicity promoted by $\alpha$-syn occur only at the cytoplasm (Pacheco et al. 2012). However, several studies have found the presence of extracellular $\alpha$-syn, suggesting that the neurotoxic effects of $\alpha$-syn might also occur in the extracellular space through unknown mechanisms (Bidinosti et al. 2012, El-Agnaf et al. 2003, El-Agnaf et al. 2006, Paleologou et al. 2009, Tokuda et al. 2010). Previous studies have shown that $\alpha$-syn alters membrane permeability through the formation of ion permeable pores (Feng et al. 2010, Schmidt et al. 2012, Volles \& Lansbury 2002, Volles \& Lansbury 2003, Tsigelny et al. 2012, Kim et al. 2009, Kostka et al. 2008, Quist et al. 2005, Tsigelny et al. 2007, van Rooijen et al. 2010, Zakharov et al. 2007). Although this is an attractive idea to explain part of the associated 
neurotoxicity of $\alpha$-syn, it has never been demonstrated to occur in neuronal membranes exposed directly to extracellular $\alpha$-syn oligomers (Tsigelny et al. 2012, Lashuel et al. 2013).

Using a variation of the patch clamp technique, denominated the perforated configuration, we found that $\alpha$-syn oligomers rapidly form "pore-like structures" in the membrane of hippocampal and dopaminergic neurons, suggesting that extracellular actions of $\alpha-$ syn can be mediated by direct changes in the neuronal plasma permeability.

\section{Material and Methods}

\section{Primary cultures of rat hippocampal neurons}

Hippocampal neurons were obtained from 18-day pregnant rat embryos Sprague-Dawley as previously described (Tapia et al. 2001) in accordance with NIH recommendations. All animals were handled in strict accordance with the Animal Welfare Assurance (permit number 2008100A) and all animal work was approved by the appropriate Ethics and Animal Care and Use Committee of the University of Concepcion. Cells were maintained with $5 \% \mathrm{CO}_{2}$ at $37^{\circ} \mathrm{C}$. All experiments were performed at 10-13 DIV.

\section{Slices preparation and dissociation}

Slices of $300 \mu \mathrm{m}$ were obtained from substantia nigra (P20) of C57BL/6 mice using Leica VT1200S vibratome in cutting solution (in mM: sucrose 194, $\mathrm{NaCl} 30, \mathrm{KCl} 4.5,1 \mathrm{MgCl}_{2}$, $\mathrm{NaHCO}_{3} 26, \mathrm{NaH}_{2} \mathrm{PO}_{4} 1.2$ and glucose 10 ). The slices were incubated on artificial cerebrospinal fluid solution (aCSF) (in mM: $\mathrm{NaCl} 124, \mathrm{KCl} 4.5, \mathrm{MgCl}_{2}$ 1, $\mathrm{NaHCO}_{3} 26, \mathrm{NaH}_{2} \mathrm{PO}_{4} 1.2$, glucose $10, \mathrm{CaCl}_{2} 2$ ) saturated with $95 \% \mathrm{O}_{2} / 5 \% \mathrm{CO}_{2}$ for $1 \mathrm{~h}$ at $37^{\circ} \mathrm{C}$. Then the slices were mechanically dissociated with a curved tip glass pipette at a frequency of $5 \mathrm{~Hz}$, breaking up the desired area by 
histological identification. To adhere the dissociated cells to well plate was necessary to wait for 15 minutes before electrophysiological recording in external solution.

\section{In vitro preparation of $\alpha$-syn}

Recombinant human $\alpha$-syn (1-140) was purchased from Anaspec (CA, USA). $\alpha$-syn was dissolved in sterile water and stored in aliquots at $346 \mu \mathrm{M}$ and kept at $-20^{\circ} \mathrm{C}$. The aliquots were then diluted in DPBS (Dulbecco's Phosphate-Buffered Saline; Gibco, USA) at pH 4.0, leaving a soluble protein stock of $59 \mu \mathrm{M}$ that was maintained at $4^{\circ} \mathrm{C}$ before the oligomerization process (up to $10 \mathrm{~min}$ ). For the formation of oligomers, $\alpha$-syn was stirred vertically at $800 \mathrm{rpm}$ at $37^{\circ} \mathrm{C}$ for $24 \mathrm{~h}$ in a Thermomixer Compact (Eppendorf).

\section{Western Blots}

Standard Western blotting procedures were used. Equal amounts of protein were separated on Tris-tricine gels. Protein bands were transferred onto nitrocellulose membranes, blocked with 5\% milk and incubated with a primary antibody using the following concentrations: anti- $\alpha$-syn (211) 1:1000 (Santa Cruz Biotechnology, CA, USA) and anti- $\beta$-actin 1:1000 (Santa Cruz Biotechnology, CA, USA) and the corresponding secondary antibody. Immunoreactive bands were visualized with ECL plus Western Blotting Detection System (PerkinElmer, MA, USA).

\section{Patch Clamp Recordings}

Patch pipettes having a resistance of $\sim 5 \mathrm{M} \Omega$ were prepared from filament-containing borosilicate micropipettes. Perforated recordings were obtained as follows: the perforating agent was added into the pipette solution and a $5 \mathrm{mV}$ pulse was used to monitor the perforation using an Axopatch 
200B (Molecular Devices, USA) amplifier as previously described (Sepulveda et al. 2010). The solutions used were; external solution: $150 \mathrm{mM} \mathrm{NaCl}, 5.4 \mathrm{mM} \mathrm{KCl}, 2.0 \mathrm{mM} \mathrm{CaCl} 2,1.0 \mathrm{mM}$ $\mathrm{MgCl}_{2}, 10 \mathrm{mM}$ glucose and $10 \mathrm{mM}$ HEPES (pH 7.4, $\left.330 \mathrm{mOsmol}\right)$ and internal solution in the patch pipette: $120 \mathrm{mM} \mathrm{KCl}, 4.0 \mathrm{mM} \mathrm{MgCl} 2,10 \mathrm{mM}$ BAPTA and $2.0 \mathrm{mM} \mathrm{Na} 2-\mathrm{ATP}(\mathrm{pH}$ 7.4, 310 mOsmol).

\section{Immunofluorescence}

Hippocampal neurons were fixed for 15 minutes with paraformaldehyde at $4{ }^{\circ} \mathrm{C}$ and permeabilized with $0.1 \%$ Triton X-100 in PBS $1 \mathrm{X}$ (Phosphate buffered saline). The cells were subsequently incubated overnight with the following primary antibodies: rabbit polyclonal antibody against Microtubule Associated Protein 2 (MAP-2, 1: 400, Santa Cruz Biotechnology, CA, USA), mouse monoclonal antibody against $\alpha$-syn $(211 ; 1$ : 300, Santa Cruz Biotechnology, CA, USA), mouse monoclonal antibody against Synaptosomal-associated protein 25 (SNAP25, 1: 50, Synaptic System, USA) and mouse monoclonal antibody against Synaptic Vesicle 2 (SV2, 1: 200). In order to visualize the binding of the primary antibody, the cells were incubated with the corresponding second antibody conjugated to FITC or Cy3 (Jackson ImmunoResearch Laboratories, West Grove, PA). Then, the nuclei were stained with 4',6-diamidino-2phenylindole (DAPI, $300 \mathrm{nM}$, Invitrogen, USA) for 1-2 minutes and washed with PBS 3 times for 5 minutes. Finally, the cells were mounted onto slides using Dako Fluorescent Mounting Media (Dako, North America, Inc, CA, USA) and the images were obtained using a laser scanning microscope LSM780 (63X oil immersion objective, Zeiss, Germany). Images processing was made with ImageJ 1.47 (NIH, USA).

\section{Intracellular Calcium Imaging}


Hippocampal neurons were loaded with Fluo-4 AM (1 $\mu \mathrm{M}$ in pluronic acid/ DMSO, Molecular Probes, Eugene, OR, USA) for 20 minutes at $37^{\circ} \mathrm{C}$. The cells were then washed once with DPBS and incubated for 20 minutes at $37^{\circ} \mathrm{C}$. Then were placed on an inverted fluorescent microscope (Eclipse TE, Nikon, USA) and briefly illuminated (200 ms) using a computer-controlled Lambda 10-2 filter wheel (Sutter Instruments, USA). Regions of interest (ROI) were marked in a field having usually more than 10 cells. Images for total intracellular calcium levels were collected at $20 \mathrm{~s}$ intervals during a continuous $6000 \mathrm{~s}$ period and for calcium transients (hippocampal neurons) were collected at $2 \mathrm{~s}$ intervals during 5 minutes. The imaging was carried out with SensiCam camera (PCO, Germany) using Axon Instruments Workbench 2.2 software.

\section{FM1-43 Loading and Unloading}

Presynaptic vesicles were labeled by exposure to styryl dye FM1-43 (10 $\mu \mathrm{M}$; MolecularProbes) during a high $\mathrm{K}^{+}$depolarization for 5 minutes and washed immediately. Coverslips were mounted on a rapid switching flow perfusion chamber with an epifluorescence microscope (Nikon Eclipse 3000). Depolarization-dependent destaining was induced by bath perfusion with $60 \mathrm{mM} \mathrm{K}^{+}$(equiosmolar replacement of $\mathrm{Na}^{+}$).

\section{Data analysis}

Statistical analyzes were performed using the One-way ANOVA expressed as the mean \pm SEM. A level of $\mathrm{p}<0.05$ was considered statistically significant $(*)$ followed by the Bonferroni post test. The fluorescence was normalized with respect to the initial fluorescence signal and analyzed using GraphPad Prism5. 


\section{Results}

\section{$\alpha$-syn oligomers are predominantly soluble}

Firstly, we characterized $\alpha$-syn oligomers using western blot. The results showed the presence of SDS-resistant $\alpha$-syn high molecular weight species after the oligomerization process, which were not detected in freshly dissolved $\alpha$-syn (Fig. 1A). After the oligomerization procedure and using negative and immunogold staining for anti- $\alpha$-syn antibody, an antibody raised against aminoacid 121-125 of human $\alpha$-syn, (211; Santa Cruz Biotechnology, CA, USA), we did not find evidence for the existence of fibrillar structures after $24 \mathrm{~h}$ of stirring, which was in agreement with the absence of birrefringent congophilic oligomers (data not shown). This result was in agreement with the fact that $\alpha$-syn oligomers were mainly found in the soluble fraction obtained after 15 minutes of centrifugation at $10.000 \mathrm{rpm}$ (Fig. 1B). Thus, the results show that recombinant $\alpha$-syn used in this study is a mixture of non fibrillar molecular forms; and rich in low molecular weight oligomers with stable conformations as they do not disassemble under denaturating western blot conditions. Moreover, we found that these type of $\alpha$-syn oligomers rapidly associated to neuronal cultures (Fig. 1C, D), suggesting that they could potentially trigger signaling at the plasma membrane. 
Once $\alpha$-syn binds to the neuronal membrane, how can extracellular $\alpha$-syn affect synaptic and cellular functions? One possible mechanism is that $\alpha$-syn associates to the plasma membrane inducing membrane thinning in a detergent-like process. Conversely, it may insert itself in the membrane and form "pore-like structures" (Feng et al. 2010, Schmidt et al. 2012, Volles \& Lansbury 2002, Volles \& Lansbury 2003, Tsigelny et al. 2012, Kim et al. 2009, Kostka et al. 2008, Quist et al. 2005, Tsigelny et al. 2007, van Rooijen et al. 2010, Zakharov et al. 2007, Lashuel et al. 2002, Lashuel et al. 2013). Currently, electrophysiological studies utilize antifungal antibiotics to perforate cell membranes and record whole cell ionic currents with the patch clamp technique, a variant known as a perforated recording configuration (Sepulveda et al. 2010) (Fig. 2A). Therefore, to test if $\alpha$-syn oligomers could affect the membrane conductance by forming membrane perforations, we added the protein to the patch pipette and examined if pore/perforates formed in the hippocampal cells. The data revealed that, when using a control solution (vehicle) in the patch pipette, stable recordings were obtained for 20 or more minutes (Fig. 2B, C). For example, application of a $5 \mathrm{mV}$ voltage pulse produced a very small charge, mainly from a partly compensated electrode capacitance. This charge transferred was significantly increased 5 fold over control when $0.5 \mu \mathrm{M} \alpha$-syn oligomers were added into the patch pipette solution, after 20 minutes of recording. This effect was not found when $\alpha$-syn was not stirred (freshly dissolved), suggesting that soluble non-oligomerized $\alpha$-syn is not active. Nevertheless, the charge induced by $\alpha$-syn oligomers was smaller (30\%) than that produced by breaking the membrane with a pulse of negative pressure (whole-cell configuration). In agreement with the notion that this effect was mediated by the toxic protein, the action of $\alpha$-syn was blocked by co-incubation with the anti $\alpha$-syn 211 antibody. Furthermore, to determine whether $\alpha$-syn oligomers allowed the entry of biologically active molecules into the cell making the membrane more permeable, we added the fluorescent non hydrolyzable glucose analog, 6- 
NBDG (van der Waals diameter of $\sim 1 \mathrm{~nm}$ ), into the patch pipette. The data showed that the application of $\alpha$-syn oligomers caused a 5 fold rise in the relative fluorescence units as compared to control, a result that correlates well with the increase in capacitative current found (Fig. 2D, E). The effect of $\alpha$-syn oligomers in the increase of 6-NBDG-induced fluorescence was completely blocked with the $211 \alpha$-syn antibody. Therefore, these data suggest the presence of a large membrane rupture caused by $\alpha$-syn oligomers allowing the passage of molecules of up to $\sim 1 \mathrm{~nm}$ in diameter. The perforation properties of $\alpha$-syn was also observed in dissociated P20 dopaminergic neurons (Fig. 3), indicating that the permeability of more mature neuronal plasma membrane are prone to be affected by the presence of extracellular $\alpha$-syn.

\section{The association of $\alpha$-syn to the neuronal plasma membrane}

One of the first steps for the formation of "pore-like structures" in the membrane is the association of $\alpha$-syn oligomers to the plasma membrane (Pacheco et al. 2012). This association between amyloidogenic proteins and the plasma membrane result in mutually disruptive structural perturbations (Relini et al. 2009). Therefore, the sensitivity of hippocampal neurons to the formation of $\alpha$-syn "pore-like structures" might be due to association to the plasma membrane. To address this possibility, we used indirect immunofluorescence to examine the association of $\alpha$-syn $(0.5 \mu \mathrm{M})$ to hippocampal neurons for $1 \mathrm{~h}$ at $37^{\circ} \mathrm{C}$ (Fig. 4). The confocal microscopy analysis showed that association of $\alpha$-syn to hippocampal neurons had a punctate appearance (Fig. 4), which was not found in GFAP-positive glial cells (data not shown). The examination of image stacks at different cell levels support the notion that $\alpha$-syn associated 
mainly to the cell surface in hippocampal neurons (Fig. 4H). Overall, these results confirm that the neuronal plasma membrane is a plausible site of action for extracellular $\alpha$-syn.

\section{Extracellular $\alpha$-syn increases intracellular calcium in hippocampal neurons}

There is some evidence supporting the involvement of calcium in PD (Danzer et al. 2007). Interestingly, it was recently described that amyloid $\beta$-peptide $(\mathrm{A} \beta)$ oligomers (associated to Alzheimer's Disease) form pore-like structures that disrupt neuronal membranes (Sepulveda et al. 2010), promoting a rapid increase in intracellular calcium levels and a subsequent decrease in presynaptic and postsynaptic proteins in primary hippocampal neurons (Parodi et al. 2010, Sepulveda et al. 2010). Therefore, we decided to study the effect of extracellular $\alpha$-syn in intracellular calcium levels in hippocampal neurons. Perfusion of $\alpha$-syn $(0.5 \mu \mathrm{M})$ onto hippocampal neurons caused an increase in intracellular calcium levels that began approximately 10 minutes after addition of $\alpha$-syn, and reached values of 1.7 fold over control after 75 minutes of recording (Fig. 5). To test if the increase in intracellular calcium was associated to external calcium entry by voltage-dependent calcium channels, we used cobalt $(20 \mu \mathrm{M})$, a non-specific voltage-gated calcium channel blocker (Relini et al. 2009), in the normal external solution before applying $\alpha$-syn oligomers. These data also shows that the increase in intracellular calcium levels in hippocampal neurons was sustained in the presence of cobalt (Fig. 5). Moreover, in the absence of external calcium solution $\alpha$-syn oligomers did not change intracellular calcium levels, confirming that the increase in intracellular calcium levels by $\alpha$-syn oligomers was only product of external calcium entry (data not shown). Therefore, these results suggest that $\alpha$-syn pores, 
independent of the activation of voltage-dependent calcium channels, might be implicated in the increment in intracellular calcium levels in hippocampal neurons.

\section{Extracellular $\alpha$-syn alters synaptic transmission in hippocampal neurons}

It seemed feasible that the increment in intracellular calcium could affect the release of synaptic vesicles, thus affecting synaptic transmission. We found that $\alpha$-syn oligomers produced an increase in the frequency of calcium transients, reaching a maximum of 3 fold compared to controls after $3 \mathrm{~h}$ of incubation (Fig. 6A, B). This effect was associated to a 2.5 fold increase in the frequency of miniature synaptic currents, without significant changes in the amplitude (Fig. 6C, D). In addition, we also wanted to determine if these increases in synaptic current activity were accompanied by changes in synaptic proteins. To achieve this, used an antibody that recognizes the SNAP25 presynaptic protein, a component of the SNARE complex, which facilitates the association between synaptic vesicles and plasma membrane (Sharma et al. 2011). Quantitative immunofluorescent analysis of confocal microscopy revealed that $\alpha$-syn oligomers produced a statistically significant increase in SNAP25 staining after $3 \mathrm{~h}$ of exposure $(66 \pm 18 \%$ over control; Fig. 7A, B). To determine if the increase in SNAP25 was accompanied by an increase in synaptic release upon presynaptic depolarization with high $\mathrm{K}^{+}$, we carried out experiments using the fluorescent probe FM1-43 (Fig. 7C). Control and treated $\alpha$-syn neurons were charged with FM1-43 and subsequently exposed to a pulse of $60 \mathrm{mM} \mathrm{K}$ solution, a treatment that caused a decrease in the measured fluorescence. The data showed that after treatment with $\alpha$-syn oligomers, hippocampal neurons displayed a greater decay in fluorescence associated to FM1-43 (Fig. $7 \mathrm{C}$ ), with values $\left(\Delta \mathrm{F} / \mathrm{F}_{0}\right)$ of $0.71 \pm 0.02$ for control condition and $0.64 \pm 0.01$ for neurons treated with $\alpha$-syn after $300 \mathrm{~s}$ of recording, indicating that $\alpha$-syn facilitated the release of synaptic vesicles. 
Taken together, these results indicate that nanomolar concentrations of $\alpha$-syn can positively modify presynaptic components, thus facilitating synaptic neurotransmission. To test if prolonged exposure of hippocampal neurons to extracellular $\alpha$-syn oligomers could promote synaptotoxicity, the cells were incubated for $24 \mathrm{~h}$ with $\alpha$-syn $(5 \mu \mathrm{M})$. Then, the immunoreactivity of a synaptic vesicle membrane protein, SV2, was used as a marker for synaptotoxicity (Parodi et al. 2010). We have previously shown that SV2 levels are decreased in hippocampal neurons exposed to perforating agents (Parodi et al. 2010, Peters et al. 2013, Sepulveda et al. 2014). Under these conditions, a strong decrease in SV2 immunoreactivity was observed in $\alpha$-syntreated neurons (Fig. 8), which supports an extracellular mechanism to explain the neurodegenerative features associated to extracellular $\alpha$-syn accumulation.

\section{Discussion}

\section{a-syn associates to neurons and causes membrane leakage}

Current evidence support the idea that oligomeric forms of $\alpha$-syn are able to alter membrane permeability via pore generation (Feng et al. 2010, Kim et al. 2009, Kostka et al. 2008, Quist et al. 2005, Schmidt et al. 2012, Tsigelny et al. 2007, van Rooijen et al. 2010, Volles \& Lansbury 2002, Zakharov et al. 2007). Whether pore formation and its subsequent cellular impact can also occur in neuronal membranes exposed to extracellular $\alpha$-syn is not completely clear (Pacheco et al. 2012). Interestingly, another member of the synuclein family, $\gamma$-synuclein is able to aggregate and forms annular structures, which can form pores, incorporate in cell membrane and affect ion homeostasis (Surgucheva et al. 2012). In the present study, which combined confocal microscopy and patch clamp techniques, we showed that $\alpha$-syn associated to the plasma membrane of hippocampal neurons in a punctate fashion leading to the formation of "pore-like 
structures", increasing membrane conductance and the influx of a large fluorescent glucose analog.

The present results are significant because they help to understand the pathological nature of extracellular $\alpha$-syn, as they indicate that molecules with biological functions, such as glucose, could diffuse freely from the cytoplasm through large membrane disruptions promoted by these oligomers. Our data support the formation of large perforations in the cellular plasma membrane, with an estimated minimal inner diameter near $\sim 1 \mathrm{~nm}$, as evidenced by intracellular 6-NBDG fluorescence. These results agree with previous studies using AFM and molecular dynamics that showed that $\alpha$-syn was able to form a molecular structures resembling large pores in lipid membranes (Quist et al. 2005, Tsigelny et al. 2007, Tsigelny et al. 2012) and another publication that indicated that neurons overexpressing $\alpha$-syn display a high permeability to calcein (Tsigelny et al. 2012). According to studies using electron microscope, a maximal diameter of $2.5 \mathrm{~nm}$ is expected for $\alpha$-syn perforates (Lashuel et al. 2002). Thus it is possible that because these studies have been performed in artificial settings, the diameter of $\alpha$-syn perforates could be different in native conditions. The topology and structural details of the $\alpha$-syn perforate or pore-like structures formed in neuronal membranes need to be solved in the future and is beyond the present study. Moreover, further studies with labeled molecules of different diameters will be necessary to estimate the maximal diameter that $\alpha$-syn pores can form in native plasma membrane domains.

\section{Mechanism of action of $\alpha$-syn}

Calcium has critical roles in many neuronal functions, including synaptic transmission and plasticity, and cell survival (Mattson 2007). We found that $\alpha$-syn disrupted the membrane forming "pore-like structures", allowing an increase in intracellular calcium, with a subsequent 
increase in synaptic transmission related to a primary effect on presynaptic release. Indeed, incubation of hippocampal neurons with $\alpha$-syn caused an increase in several neuronal features such as calcium transient frequency, miniature synaptic current frequency, decay of FM1-43 fluorescence and SNAP25 staining. These findings are in agreement with results obtained with other toxic protein oligomers, such as $\mathrm{A} \beta$, which can also be inserted in the plasma membrane to make perforations (Sepulveda et al. 2010, Sepulveda et al. 2014) and alter synaptic transmission (Mattson 2007). Furthermore, a previous study showed that $A \beta$ increased the current amplitudes and calcium influx in cells expressing $\alpha$-syn, a finding consistent with the formation of cation channels, thus further supporting our hypothesis (Tsigelny et al. 2008). However, the contribution of other synaptic ions such as copper, which regulates neurotransmission (Peters et al. 2011) and is also associated to neurodegeneration (Opazo et al. 2002), cannot be ruled out of the mechanism behind $\alpha$-syn synaptotoxicity. In fact, our studies with 6-NBDG indicates that $\alpha$ syn pores can allow the passage of molecules such as glucose, which indicates that other ions or small molecules can be transported by these structures. We believe that these pore-like structures are dynamic in nature and they transit from selective (micro-perforations) to non-selective (macroperforations) states. Further studies are required to characterize the selectivity of these structures.

Synaptic dysfunction and axonopathy has been described as a possible hallmark of presymptomatic and early stage PD (Lundblad et al. 2012). This is consistent with our results where extracellular accumulation of $\alpha$-syn can promote synaptotoxicity in hippocampal neurons in chronic conditions, represented by the decrease of SV2 immunoreactivity that leads to neuronal cell loss probably due to a gain of toxic function (Burre et al. 2013). On the other hand, overexpression of human $\alpha$-syn decreased the survival and dendritic development of newborn 
neurons in the dentate gyrus (Winner et al. 2012). Therefore, the effect of extracellular $\alpha$-syn on hippocampus may explain the cognitive deficit observed in PD by a mechanism that involves changes in the permeability of the neuronal membrane ((Aarsland et al. 2007); See also references in (Pacheco et al. 2012)).

\section{Acknowledgments}

We thank Lauren Aguayo for revising the paper and Braulio Muñoz and Carolina Castillo for technical assistance. C. R. Pacheco funded by Ph.D. fellowship from CONICYT and FEBS Scholarship. This work was supported by grant Anillo-PBCT ACT-04 from the Chilean Government (LGA, CO), FONDECYT grant No 1100502 (LGA, CO) and Plan Estatal de I+D+I 2013-2016 and the ISCIII-Subdirección General de Evaluación y Fomento de la Investigación (Grants PI13/00408 and Red HERACLES RD12/0042/0014) and FEDER Funds; La Marató de TV3 ( ${ }^{\circ}$ 100310). The Florey Institute of Neuroscience and Mental Health acknowledges the strong support from the Victorian Government and in particular the funding from the Operational Infrastructure Support Grant.

\section{References}

Aarsland, D., Bronnick, K., Ehrt, U., De Deyn, P. P., Tekin, S., Emre, M. and Cummings, J. L. (2007) Neuropsychiatric symptoms in patients with Parkinson's disease and dementia: frequency, profile and associated care giver stress. J. Neurol. Neurosurg. Psychiatry, 78, $36-42$.

Bidinosti, M., Shimshek, D. R., Mollenhauer, B., Marcellin, D., Schweizer, T., Lotz, G. P., Schlossmacher, M. G. and Weiss, A. (2012) Novel one-step immunoassays to quantify $\alpha$ - 
synuclein: applications for biomarker development and high-throughput screening. $J$. Biol. Chem., 287, 33691-33705.

Braak, H., Ghebremedhin, E., Rub, U., Bratzke, H. and Del Tredici, K. (2004) Stages in the development of Parkinson's disease-related pathology. Cell. Tissue Res., 318, 121-134.

Burre, J., Vivona, S., Diao, J., Sharma, M., Brunger, A. T. and Sudhof, T. C. (2013) Properties of native brain $\alpha$-synuclein. Nature, 498, E4-6.

Danzer, K. M., Haasen, D., Karow, A. R., Moussaud, S., Habeck, M., Giese, A., Kretzschmar, H., Hengerer, B. and Kostka, M. (2007) Different species of $\alpha$-synuclein oligomers induce calcium influx and seeding. J. Neurosci., 27, 9220-9232.

El-Agnaf, O. M., Salem, S. A., Paleologou, K. E. et al. (2003) $\alpha$-synuclein implicated in Parkinson's disease is present in extracellular biological fluids, including human plasma. FASEB J., 17, 1945-1947.

El-Agnaf, O. M., Salem, S. A., Paleologou, K. E., Curran, M. D., Gibson, M. J., Court, J. A., Schlossmacher, M. G. and Allsop, D. (2006) Detection of oligomeric forms of $\alpha$ synuclein protein in human plasma as a potential biomarker for Parkinson's disease. FASEB J., 20, 419-425.

Feng, L. R., Federoff, H. J., Vicini, S. and Maguire-Zeiss, K. A. (2010) $\alpha$-synuclein mediates alterations in membrane conductance: a potential role for $\alpha$-synuclein oligomers in cell vulnerability. Eur. J. Neurosci., 32, 10-17.

Kim, H. Y., Cho, M. K., Kumar, A. et al. (2009) Structural properties of pore-forming oligomers of $\alpha$-synuclein. J. Am. Chem. Soc., 131, 17482-17489.

Kostka, M., Hogen, T., Danzer, K. M. et al. (2008) Single particle characterization of ironinduced pore-forming $\alpha$-synuclein oligomers. J. Biol. Chem., 283, 10992-11003.

Lashuel, H. A., Hartley, D., Petre, B. M., Walz, T. and Lansbury, P. T., Jr. (2002) Neurodegenerative disease: amyloid pores from pathogenic mutations. Nature, 418, 291.

Lashuel, H. A., Overk, C. R., Oueslati, A. and Masliah, E. (2013) The many faces of $\alpha-$ synuclein: from structure and toxicity to therapeutic target. Nature Rev. Neurosci., 14, $38-48$.

Lundblad, M., Decressac, M., Mattsson, B. and Bjorklund, A. (2012) Impaired neurotransmission caused by overexpression of $\alpha$-synuclein in nigral dopamine neurons. Proc. Natl. Acad. Sci. U.S.A., 109, 3213-3219.

Mattson, M. P. (2007) Calcium and neurodegeneration. Aging Cell, 6, 337-350.

Opazo, C., Huang, X., Cherny, R. A. et al. (2002) Metalloenzyme-like activity of Alzheimer's disease $\beta$-amyloid. $\mathrm{Cu}$-dependent catalytic conversion of dopamine, cholesterol, and biological reducing agents to neurotoxic $\mathrm{H}_{2} \mathrm{O}_{2}$. J. Biol. Chem., 277, 40302-40308.

Pacheco, C., Aguayo, L. G. and Opazo, C. (2012) An extracellular mechanism that can explain the neurotoxic effects of $\alpha$-synuclein aggregates in the brain. Front. Physiol., 3, 297.

Paleologou, K. E., Kragh, C. L., Mann, D. M., Salem, S. A., Al-Shami, R., Allsop, D., Hassan, A. H., Jensen, P. H. and El-Agnaf, O. M. (2009) Detection of elevated levels of soluble $\alpha$-synuclein oligomers in post-mortem brain extracts from patients with dementia with Lewy bodies. Brain, 132, 1093-1101.

Parodi, J., Sepulveda, F. J., Roa, J., Opazo, C., Inestrosa, N. C. and Aguayo, L. G. (2010) $\beta$ amyloid causes depletion of synaptic vesicles leading to neurotransmission failure. $J$. Biol. Chem., 285, 2506-2514.

Peters, C., Fernandez-Perez, E. J., Burgos, C. F., Espinoza, M. P., Castillo, C., Urrutia, J. C., Streltsov, V. A., Opazo, C. and Aguayo, L. G. (2013) Inhibition of amyloid $\beta$-induced 
synaptotoxicity by a pentapeptide derived from the glycine zipper region of the neurotoxic peptide. Neurobiol. Aging., 34, 2805-2814.

Peters, C., Munoz, B., Sepulveda, F. J., Urrutia, J., Quiroz, M., Luza, S., De Ferrari, G. V., Aguayo, L. G. and Opazo, C. (2011) Biphasic effects of copper on neurotransmission in rat hippocampal neurons. J. Neurochem., 119, 78-88.

Quist, A., Doudevski, I., Lin, H., Azimova, R., Ng, D., Frangione, B., Kagan, B., Ghiso, J. and Lal, R. (2005) Amyloid ion channels: a common structural link for protein-misfolding disease. Proc. Natl. Acad. Sci. U.S.A., 102, 10427-10432.

Relini, A., Cavalleri, O., Rolandi, R. and Gliozzi, A. (2009) The two-fold aspect of the interplay of amyloidogenic proteins with lipid membranes. Chem. Phys. Lipids, 158, 1-9.

Schmidt, F., Levin, J., Kamp, F., Kretzschmar, H., Giese, A. and Botzel, K. (2012) Singlechannel electrophysiology reveals a distinct and uniform pore complex formed by $\alpha$ synuclein oligomers in lipid membranes. PLoS One, 7, e42545.

Sepulveda, F. J., Fierro, H., Fernandez, E., Castillo, C., Peoples, R. W., Opazo, C. and Aguayo, L. G. (2014) Nature of the neurotoxic membrane actions of amyloid- $\beta$ on hippocampal neurons in Alzheimer's disease. Neurobiol. Aging, 35, 472-481.

Sepulveda, F. J., Parodi, J., Peoples, R. W., Opazo, C. and Aguayo, L. G. (2010) Synaptotoxicity of Alzheimer $\beta$ amyloid can be explained by its membrane perforating property. PLoS One, 5, e11820.

Sharma, M., Burre, J. and Sudhof, T. C. (2011) CSP $\alpha$ promotes SNARE-complex assembly by chaperoning SNAP-25 during synaptic activity. Nat. Cell. Biol., 13, 30-39.

Spillantini, M. G., Crowther, R. A., Jakes, R., Hasegawa, M. and Goedert, M. (1998) $\alpha-$ Synuclein in filamentous inclusions of Lewy bodies from Parkinson's disease and dementia with lewy bodies. Proc. Natl. Acad. Sci. U.S.A., 95, 6469-6473.

Surgucheva, I., Sharov, V. S. and Surguchov, A. (2012) $\gamma$-Synuclein: seeding of $\alpha$-synuclein aggregation and transmission between cells. Biochemistry, 51, 4743-4754.

Surguchov, A. (2013) Synucleins: are they two-edged swords? J. Neurosci. Res., 91, 161-166.

Tapia, J. C., Mentis, G. Z., Navarrete, R., Nualart, F., Figueroa, E., Sanchez, A. and Aguayo, L. G. (2001) Early expression of glycine and GABA(A) receptors in developing spinal cord neurons. Effects on neurite outgrowth. Neuroscience, 108, 493-506.

Tokuda, T., Qureshi, M. M., Ardah, M. T. et al. (2010) Detection of elevated levels of $\alpha-$ synuclein oligomers in CSF from patients with Parkinson disease. Neurology, 75, 17661772.

Tsigelny, I. F., Bar-On, P., Sharikov, Y. et al. (2007) Dynamics of $\alpha$-synuclein aggregation and inhibition of pore-like oligomer development by $\beta$-synuclein. FEBS J., 274, 1862-1877.

Tsigelny, I. F., Crews, L., Desplats, P. et al. (2008) Mechanisms of hybrid oligomer formation in the pathogenesis of combined Alzheimer's and Parkinson's diseases. PLoS One, 3, e3135.

Tsigelny, I. F., Sharikov, Y., Wrasidlo, W., Gonzalez, T., Desplats, P. A., Crews, L., Spencer, B. and Masliah, E. (2012) Role of $\alpha$-synuclein penetration into the membrane in the mechanisms of oligomer pore formation. FEBS J., 279, 1000-1013.

van Rooijen, B. D., Claessens, M. M. and Subramaniam, V. (2010) Membrane interactions of oligomeric $\alpha$-synuclein: potential role in Parkinson's disease. Curr. Protein Pept. Sci., 11, 334-342.

Volles, M. J. and Lansbury, P. T., Jr. (2002) Vesicle permeabilization by protofibrillar $\alpha-$ synuclein is sensitive to Parkinson's disease-linked mutations and occurs by a pore-like mechanism. Biochemistry, 41, 4595-4602. 
Volles, M. J. and Lansbury, P. T., Jr. (2003) Zeroing in on the pathogenic form of $\alpha$-synuclein and its mechanism of neurotoxicity in Parkinson's disease. Biochemistry, 42, 7871-7878.

Winner, B., Regensburger, M., Schreglmann, S. et al. (2012) Role of $\alpha$-synuclein in adult neurogenesis and neuronal maturation in the dentate gyrus. J. Neurosci., 32, 1690616916.

Zakharov, S. D., Hulleman, J. D., Dutseva, E. A., Antonenko, Y. N., Rochet, J. C. and Cramer, W. A. (2007) Helical $\alpha$-synuclein forms highly conductive ion channels. Biochemistry, 46, 14369-14379.

\section{Figure legends}

Figure 1. Soluble $\alpha$-syn oligomers rapidly associate to neurons. A, Western blot of freshly dissolved soluble $\alpha$-syn (left, previous to be submitted to oligomerization) and $\alpha$-syn oligomers obtained after the oligomerization process (right). B, Western blot of $\alpha$-syn oligomers after centrifugation at $10.000 \mathrm{rpm}$ for 15 minutes, $\mathrm{T}$ (total fraction), $\mathrm{S}$ (soluble) and $\mathrm{P}$ (pellet). Asteriscs depict $\alpha$-syn oligomers detected after the oligomerization process. C, Association of $\alpha$ syn oligomers to primary neuronal cultures along the time (minutes). Asteriscs depict $\alpha$-syn oligomers. D, Quantification of the $\alpha$-syn oligomers associated to primary neuronal cultures treated under the experimental conditions described in "C". The bars correspond to the mean \pm SEM obtained from 3 independent experiments $(* * p<0.01)$.

Figure 2. Effects of $\alpha$-syn on membrane conductance and a glucose analog influx in

hippocampal neurons. A, The application of perforating agents via the patch pipette causes an increase in capacitative membrane current known as Perforated Patch Clamp technique. B, Effect of the application of $\alpha$-syn oligomers through patch pipettes on capacitative membrane 
current. Note that "freshly dissolved" (soluble) $\alpha$-syn does not change the capacitative membrane current. C, Quantification of the traces recorded under the experimental conditions described in "B". The whole cell response serves as an internal control for positive membrane breakage induced by positive presure. D, Time dependent increase in cellular fluorescence associated with entry of 6-NBDG (a fluorescent nonhydrolyzable glucose analog, $10 \mathrm{nM}$ ) in presence of $\alpha$-syn oligomers $(0.5 \mu \mathrm{M})$ in the patch pipette. Preincubation of $\alpha$-syn oligomers with the specific anti $\alpha$-syn antibody 211 (1:50; Santa Cruz Biotechnology) blocked the effect on cellular fluorescence. E, Quantification of the relative fluorescence units of neuronal soma (RFU) observed under the experimental conditions described in "D". The bars are mean \pm SEM obtained from 3 independent experiments $(* * \mathrm{p}<0.01 ; * * * \mathrm{p}<0.001)$.

\section{Figure 3. Perforation of dopaminergic neuronal plasma membrane by $\alpha$-syn. A,} Representative membrane capacitive current after the application of $\alpha$-syn oligomers $(0.5 \mu \mathrm{M})$ to dissociated P20 dopaminergic neurons. B, Quantification of the traces recorded under the experimental conditions described in "A". The bars are mean \pm SEM obtained from 3 independent experiments $(* \mathrm{p}<0.05 ; * * \mathrm{p}<0.01 ; * * * \mathrm{p}<0.001)$.

Figure 4. $\alpha$-syn displays a punctate appearance on hippocampal neurons. Primary hippocampal neurons were incubated with $\alpha$-syn oligomers $(0.5 \mu \mathrm{M})$ for $1 \mathrm{~h}$ at $37^{\circ} \mathrm{C}$ and immunostained. A, Immunoreactivity associated to MAP2 (Cy3, Red). B, Immunoreactivity associated to $\alpha$-syn (FITC, Green). C, Superimposed immunofluorescent images associated to MAP2 and $\alpha$-syn. The arrows indicate the areas zoomed in D-G. D, Neuronal soma distribution 
of $\alpha$-syn. E-G, Neuronal processes associated to $\alpha$-syn. H, Serie of different optical sections $(0.4$ $\mu \mathrm{m})$ corresponding to neuronal soma indicated in "D". The confocal images are representative of at least 10 different neurons.

Figure 5. $\alpha$-syn oligomers increase intracellular calcium levels in hippocampal neurons. A, Fluo-4AM-associated fluorometric measurements showing intracellular calcium levels produced by perfusion of $\alpha$-syn oligomers $(0.5 \mu \mathrm{M})$ on hippocampal neurons incubated in external normal solution ( $\alpha$-syn $0.5 \mu \mathrm{M}$, red squares) or supplemented with cobalt $\left(\mathrm{Co}^{2+} 20 \mu \mathrm{M}+\alpha\right.$-syn $0.5 \mu \mathrm{M}$, gray triangles). Calcium levels recorded under control conditions are also shown (vehicle, black circles; $\mathrm{Co}^{2+} 20 \mu \mathrm{M}$, blue triangles). B, Quantification of data shown in "A" after 75 minutes of recording. The results are the mean \pm SEM obtained from 3 different experiments $(* * * \mathrm{p}$ $<0.001)$.

Figure 6. $\alpha$-syn oligomers increase synaptic transmission in hippocampal neurons. A, Representative traces of spontaneous calcium transients recorded from 11 DIV rat hippocampal neurons treated with $\alpha$-syn oligomers $(0.5 \mu \mathrm{M})$ for different times at $37^{\circ} \mathrm{C}$. B, Quantification of calcium transient frequency obtained under the experimental conditions shown in "A". C, Representative current traces of total miniature synaptic currents (TTX, $25 \mathrm{nM}$ ) recorded in the indicated conditions. D, Quantification of the frequency and amplitude of data obtained under the experimental conditions shown in "A". The results are the mean \pm SEM obtained from three different experiments $(* * \mathrm{p}<0.01 ; * * * \mathrm{p}<0.001)$. 
Figure 7. $\alpha$-syn oligomers increases synaptic vesicle release in hippocampal neurons. A, Confocal images of SNAP25 from 11 DIV rat hippocampal neurons treated with $\alpha$-syn oligomers $(0.5 \mu \mathrm{M})$ for $3 \mathrm{~h}$ and $24 \mathrm{~h}$ at $37^{\circ} \mathrm{C}$. B, Quantification of SNAP25/puncta observed under the experimentl conditions shown in "A" $(\mathrm{n}=10) . \mathbf{C}, \mathrm{K}^{+}$-induced destaining of FM1-43 in control and hippocampal neurons treated with $\alpha$-syn oligomers $(0.5 \mu \mathrm{M})$ for $3 \mathrm{~h}$ at $37^{\circ} \mathrm{C}$. The results are the mean \pm SEM obtained from 3 different experiments $(* \mathrm{p}<0.05 ; * * \mathrm{p}<0.01)$.

Figure 8. Chronic application of $\alpha$-syn oligomers decreases the SV2 immunoreactivity in hippocampal neurons. A and B, MAP2 (FITC, green) and SV2 (Cy3, red) immunoreactivity in hippocampal neurons untreated (A) or treated (B) with $\alpha$-syn oligomers $(5 \mu \mathrm{M})$ for $24 \mathrm{~h}$ at $37^{\circ} \mathrm{C}$. C, The graph summarizes the number of SV2 puncta observed under the experimental conditions shown in "A". The bars are mean \pm SEM obtained from three different experiments $(N=3, * p<$ $0.05)$.

Graphical abstract: We propose that $\alpha$-synuclein $\alpha$-syn) oligomers form pore-like structures in the plasma membrane of neurons from Central Nervous System (CNS). We believe that extracellular $\alpha$-syn oligomers facilitate the formation of $\alpha$-syn membrane pore-like structures, thus explaining, in part, the synaptotoxicity observed in neurodegenerative diseases characterized by its extracellular accumulation. We think that alterations in ionic homeostasis and synaptic vesicular depletion are key steps that lead to synaptotoxicity promoted by $\alpha$-syn membrane porelike structures. 
Extracellular $\alpha$-synuclein perforates neuronal plasma membrane 
A

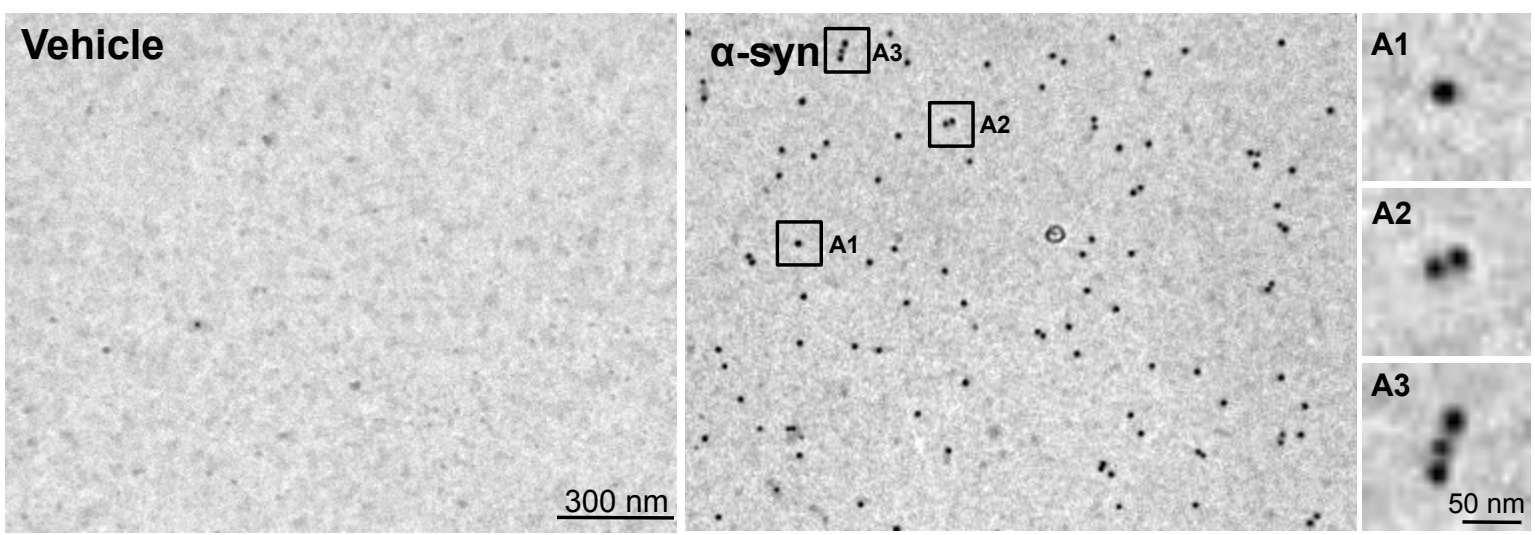

B

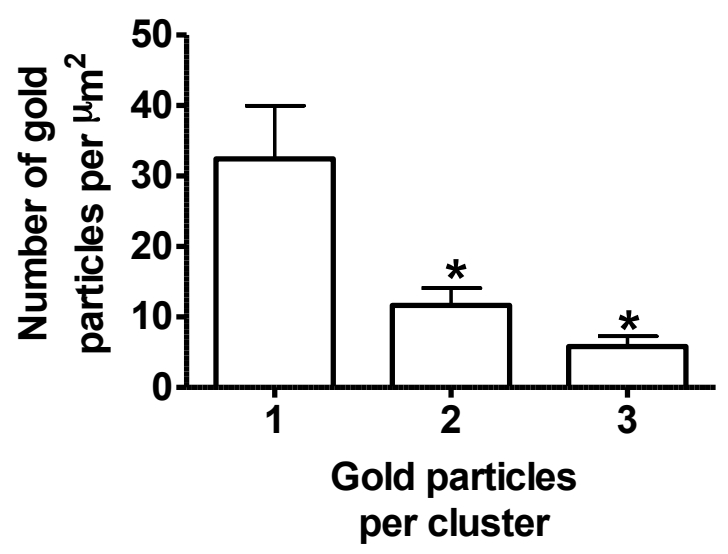

C

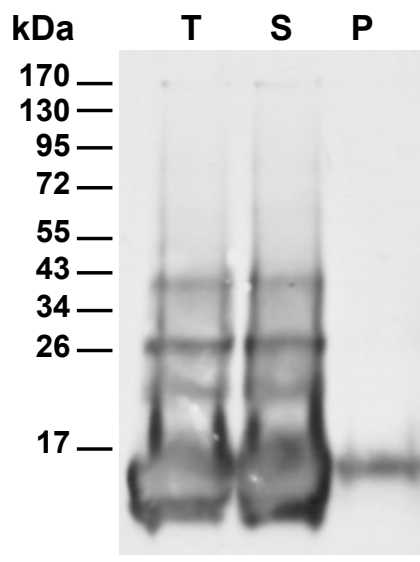

D

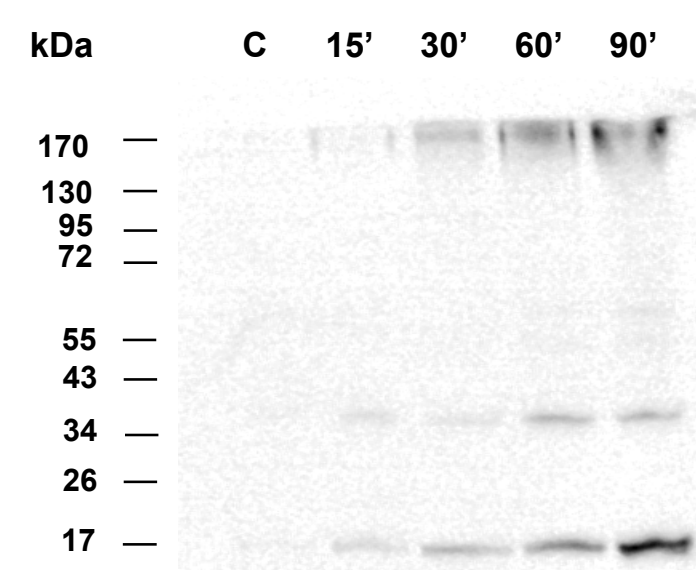

E

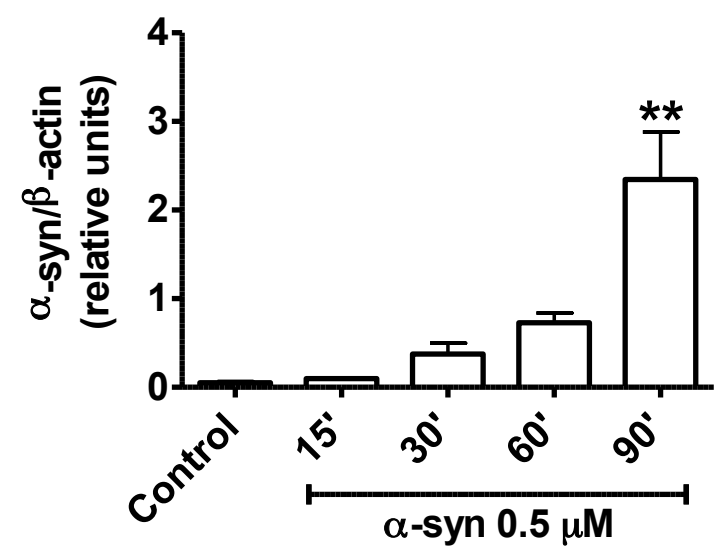

$\beta$-actin

Pacheco et al., Figure 1 
A

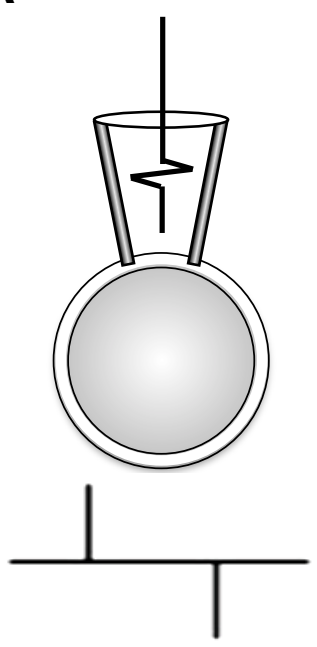

Cell attached configuration

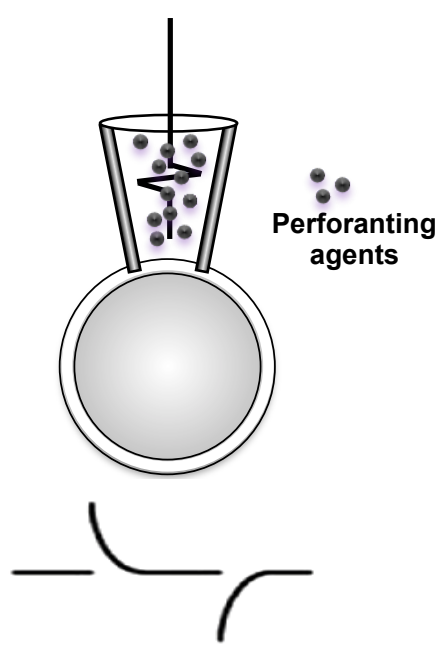

\section{Perforated configuration}

B Control
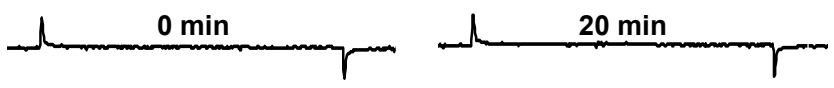

\section{a-syn $0.5 \mu \mathrm{M}$}
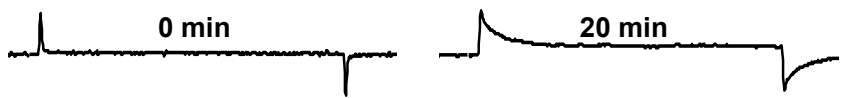

a-syn $0.5 \mu \mathrm{M}+\mathrm{A} 11$
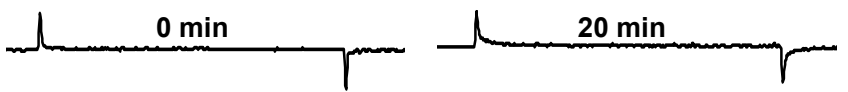

C

Whole-cell
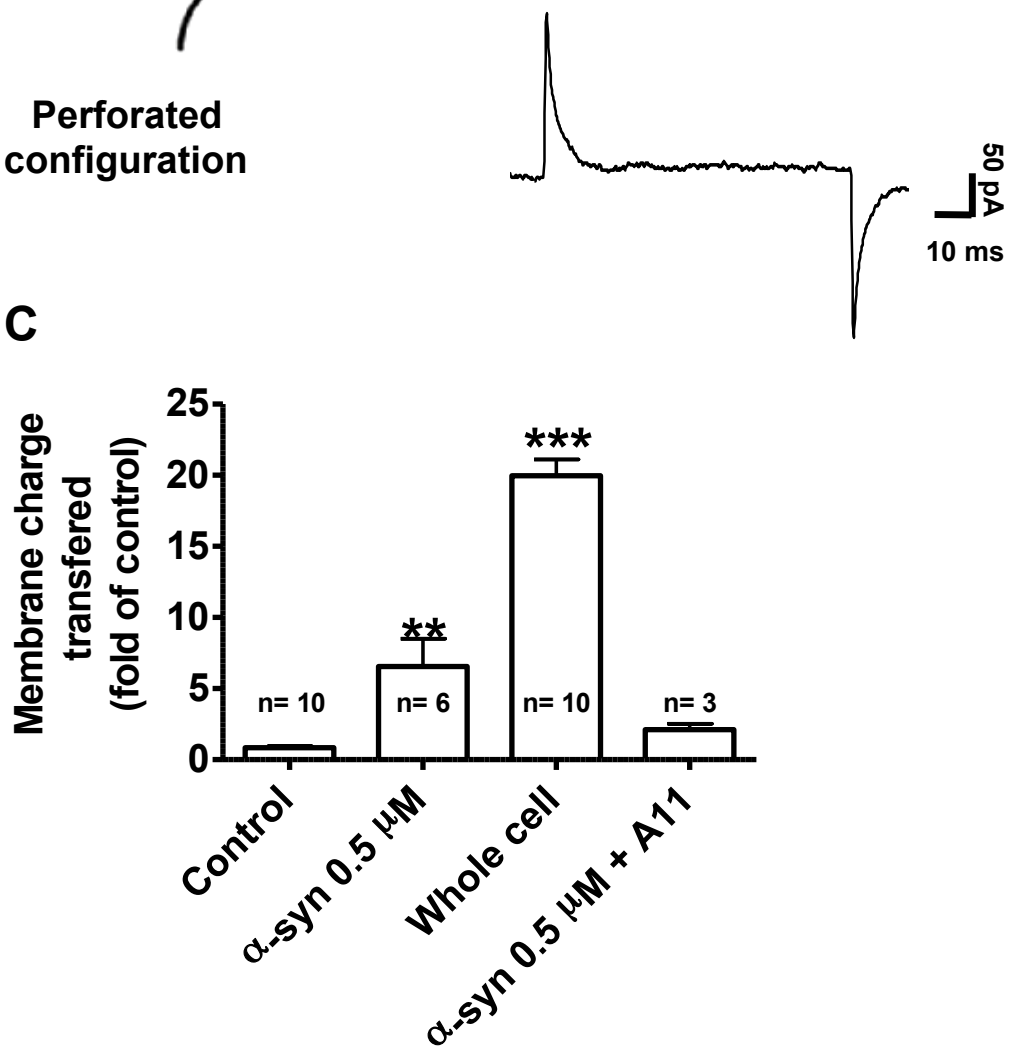

Pacheco et al., Figure 2 
A Control
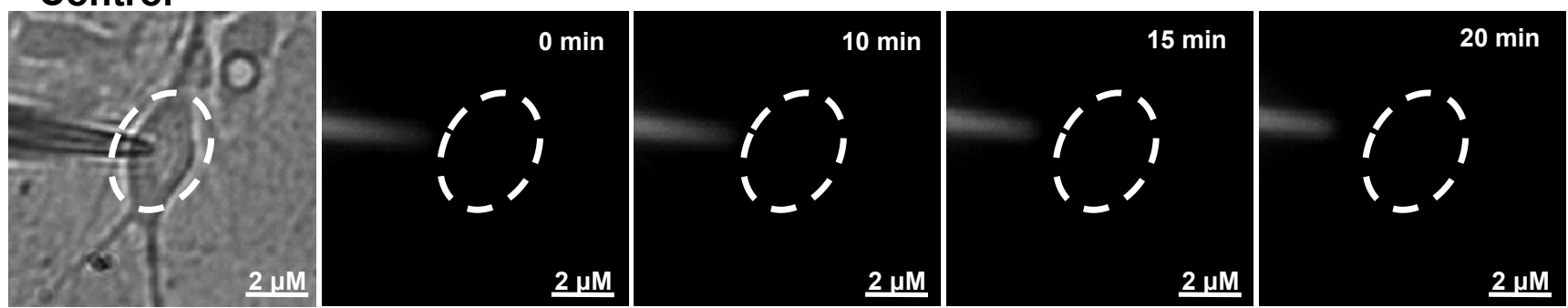

$\alpha-\operatorname{syn} 0.5 \mu M$
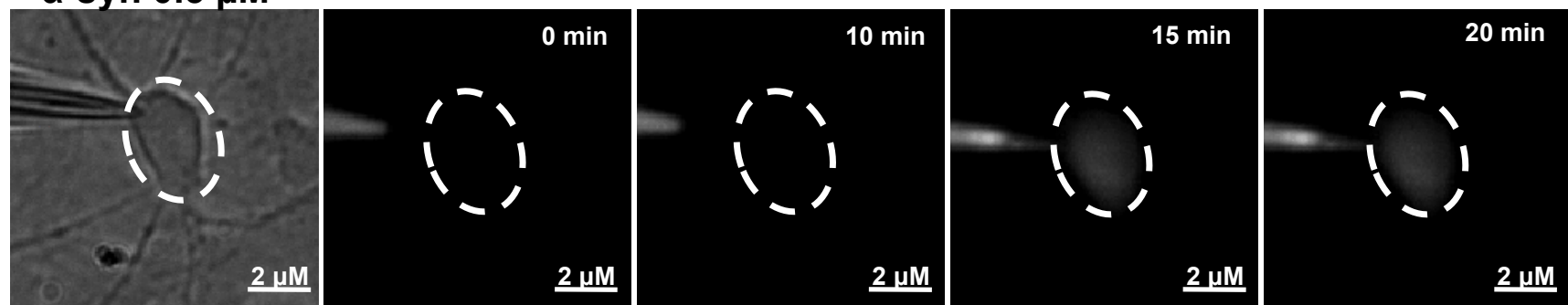

a-syn $0.5 \mu \mathrm{M}+\mathrm{A} 11$
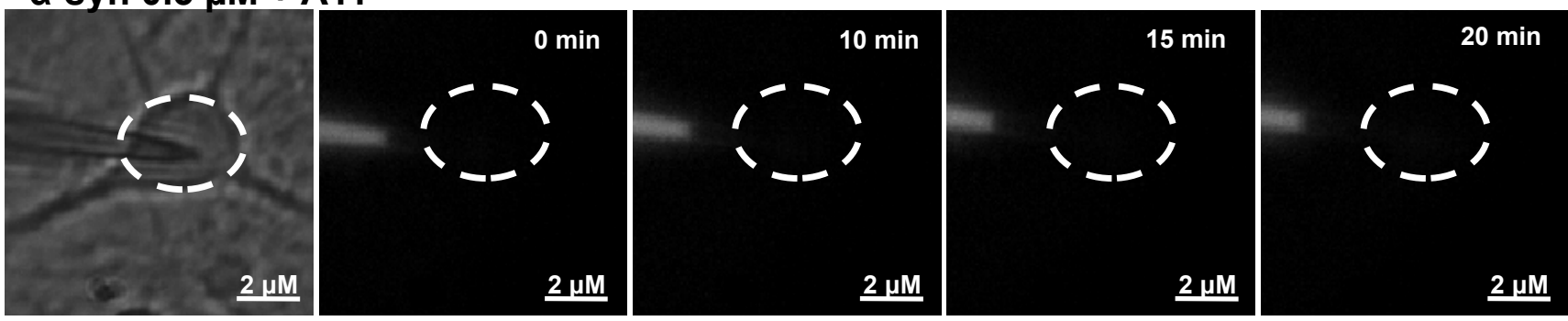

B

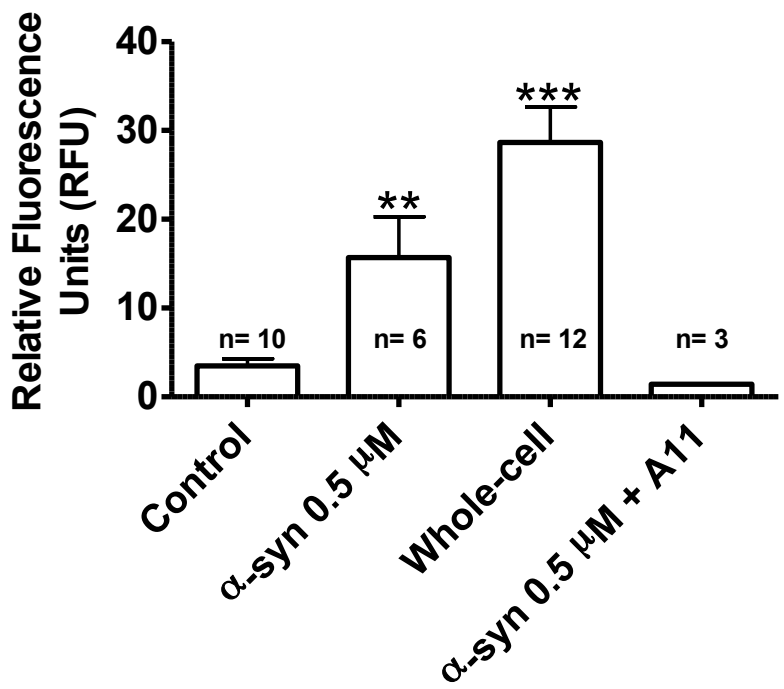

Whole-cell

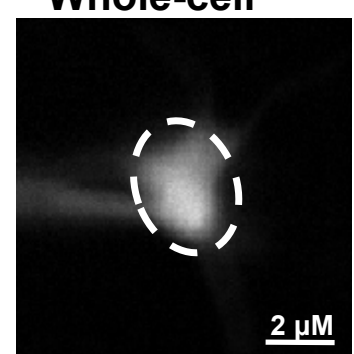

Pacheco et al., Figure 3 
RCSN-3 cells

A

Control
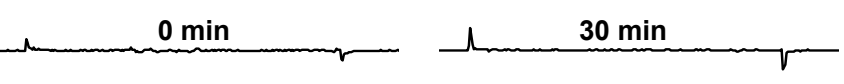

$\alpha$-syn $2.5 \mu M$

Mrm_ 0 min

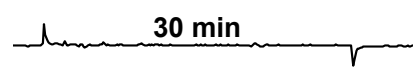

Whole-cell

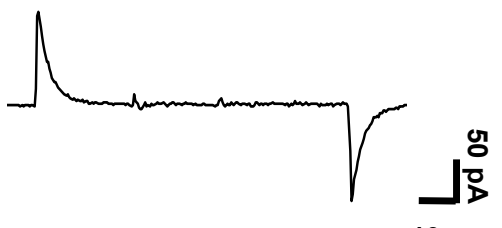

$10 \mathrm{~ms}$

Dissociated dopaminergic neurons

C

Control

a-syn $0.5 \mu \mathrm{M}$

0 min

$7 \mathrm{~min}$

Whole-cell
B

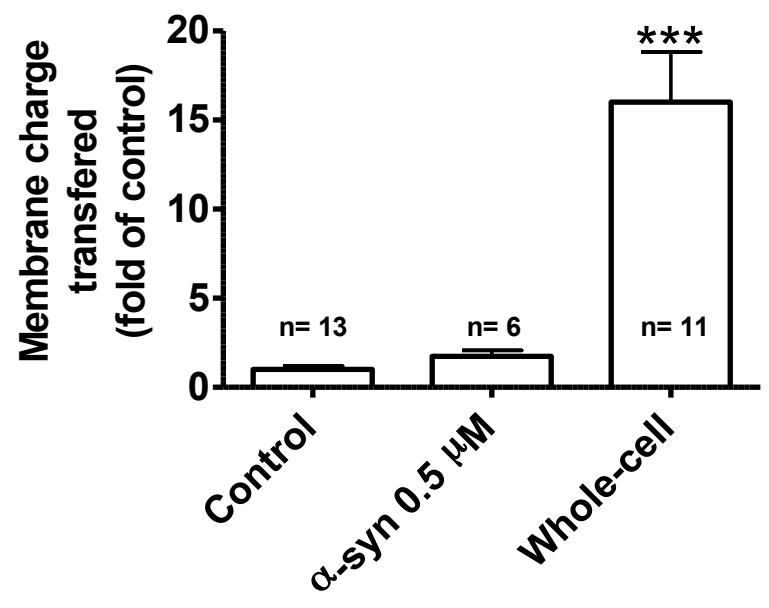

D

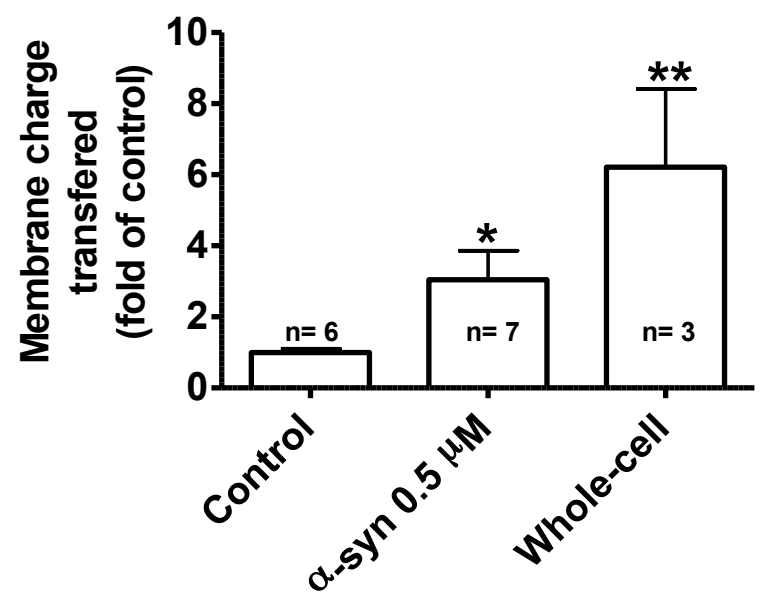

Pacheco et al., Figure 4 


\section{A}

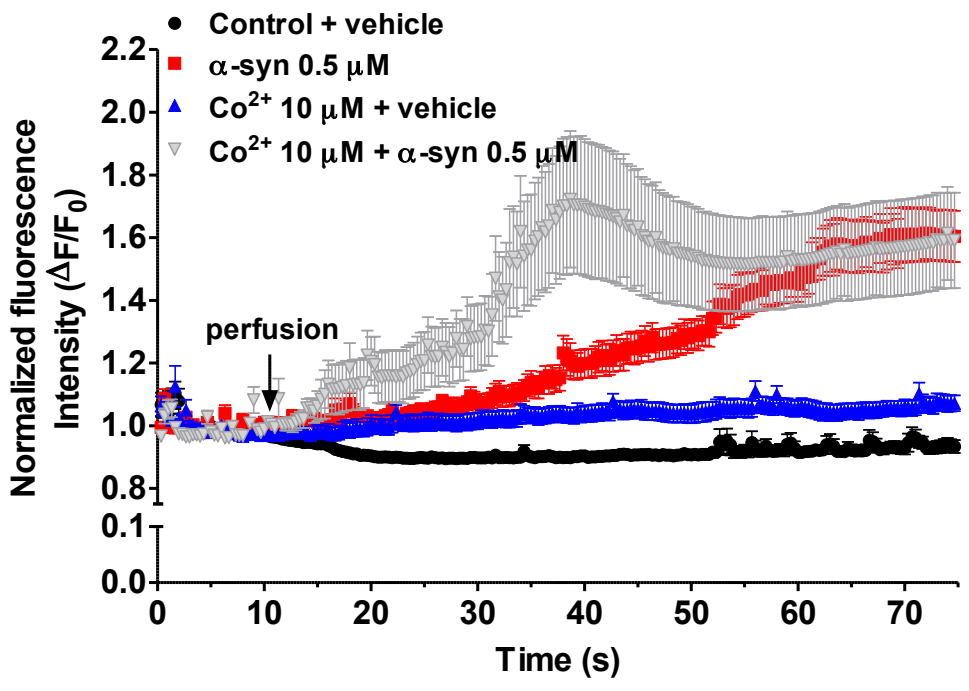

B

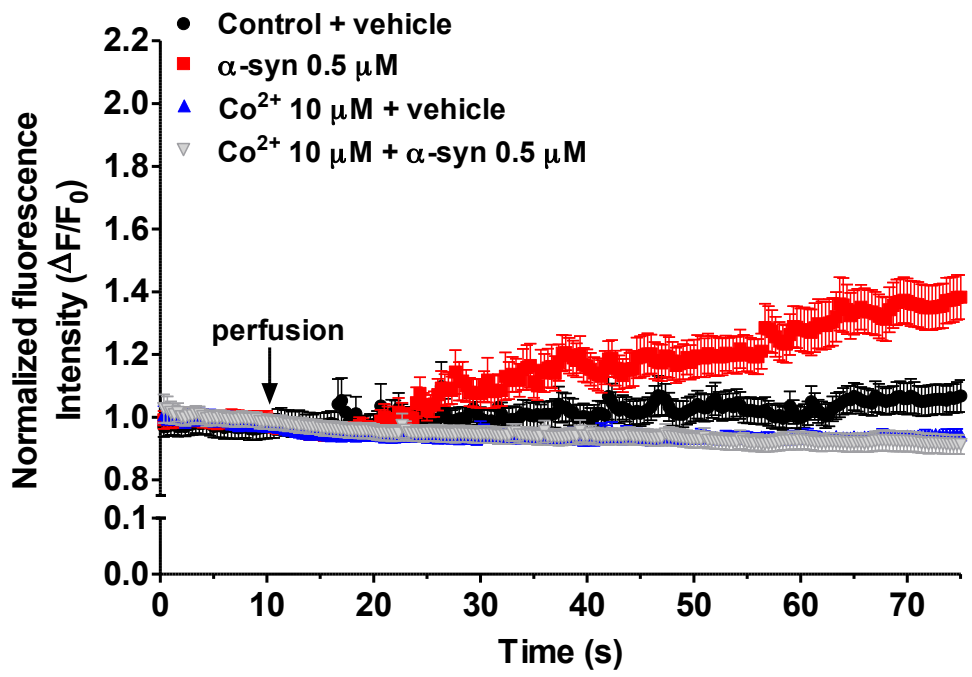

C

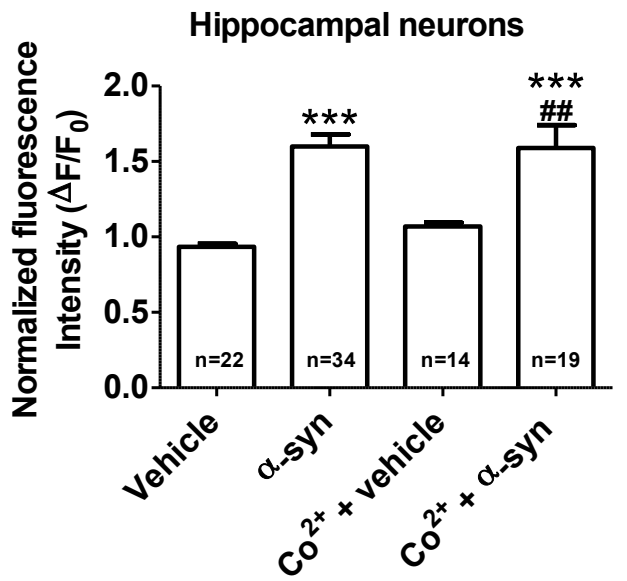

RCSN-3 cells

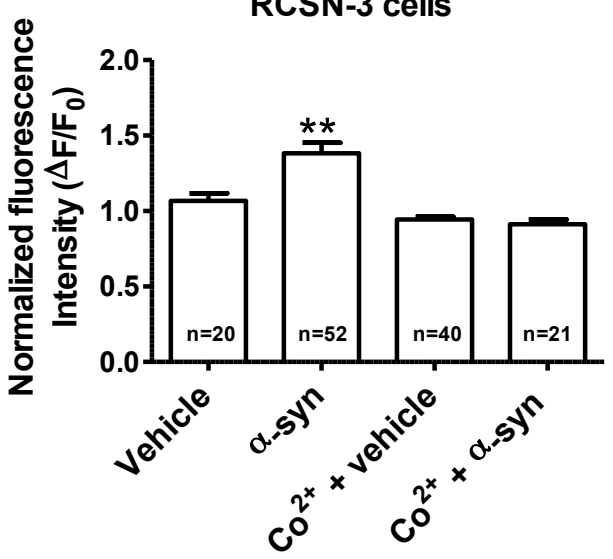


A

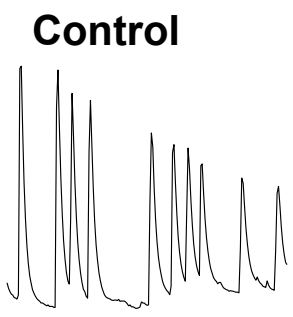

$1.5 \mathrm{~h}$
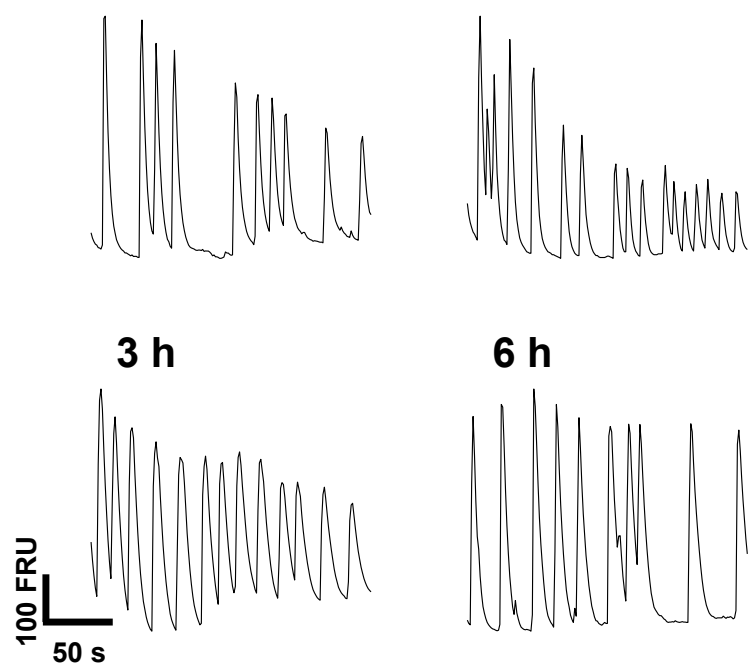

C

Control

munummonsm

$1.5 \mathrm{~h}$

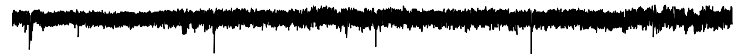

$3 \mathrm{~h}$

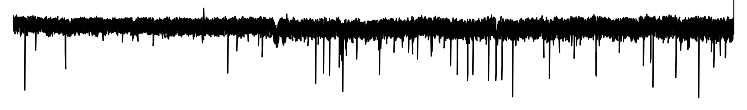

$6 \mathrm{~h}$
B

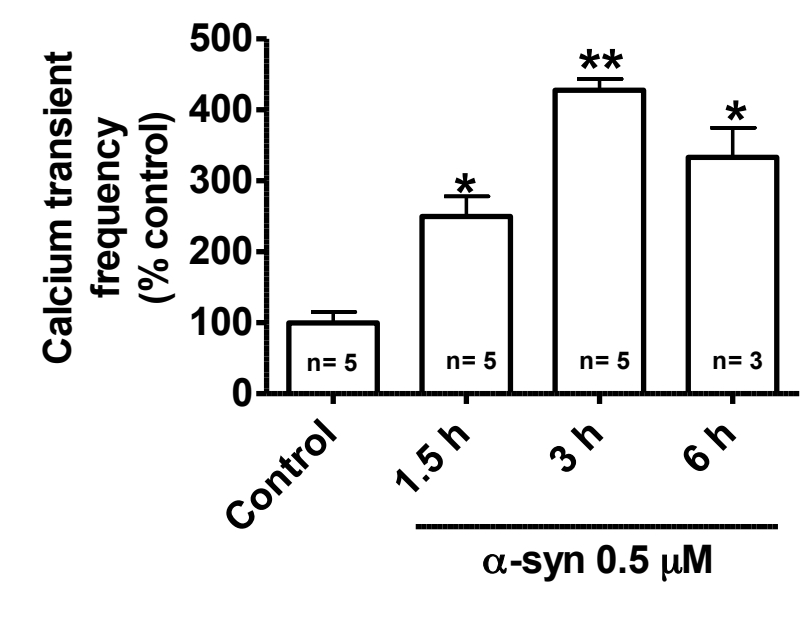

D
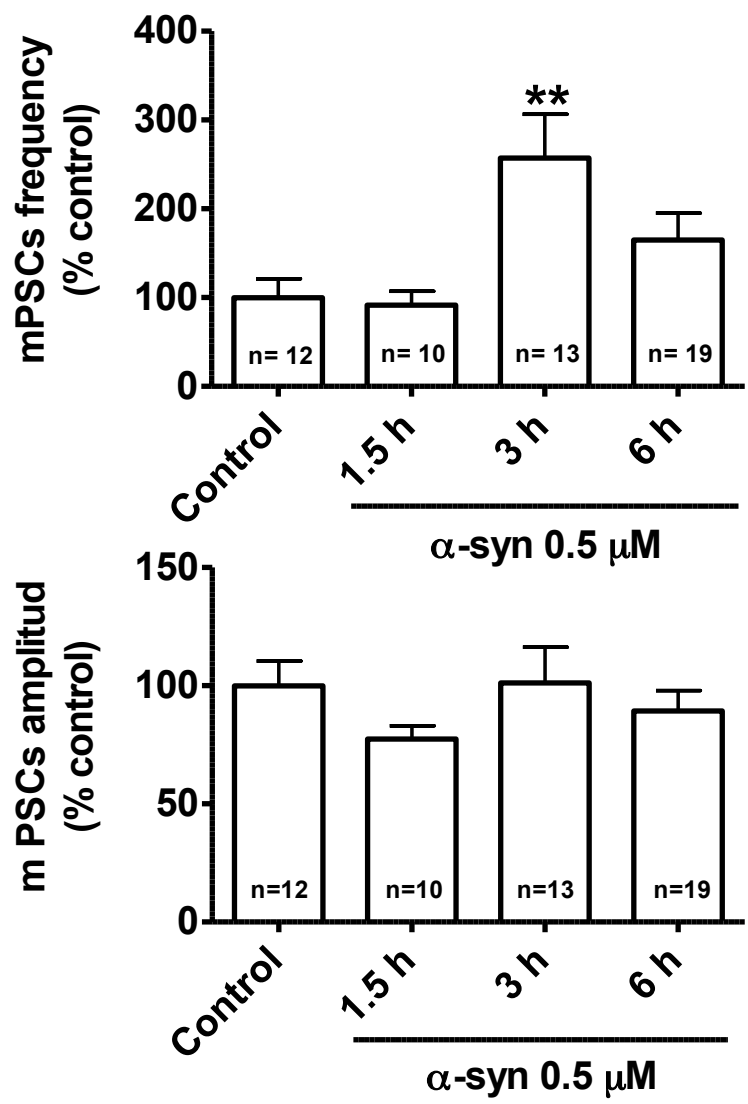

Pacheco et al., Figure 6 
A

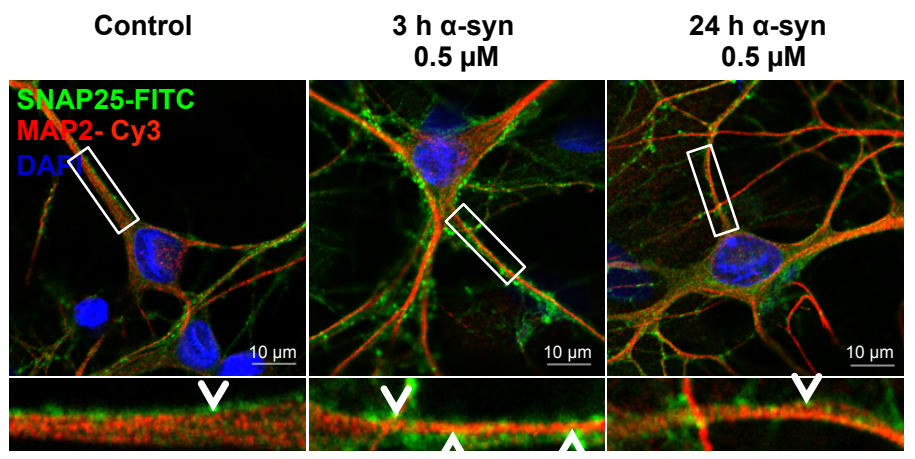

C

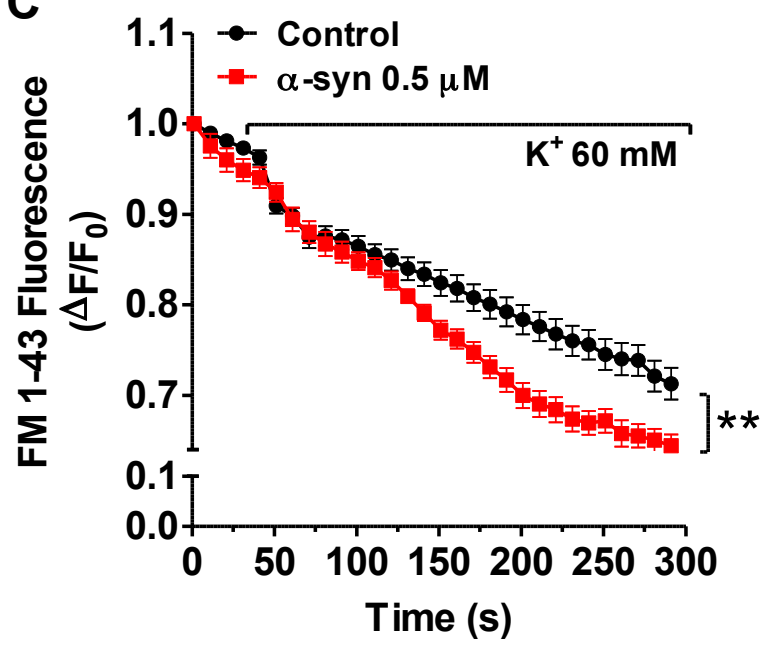

B
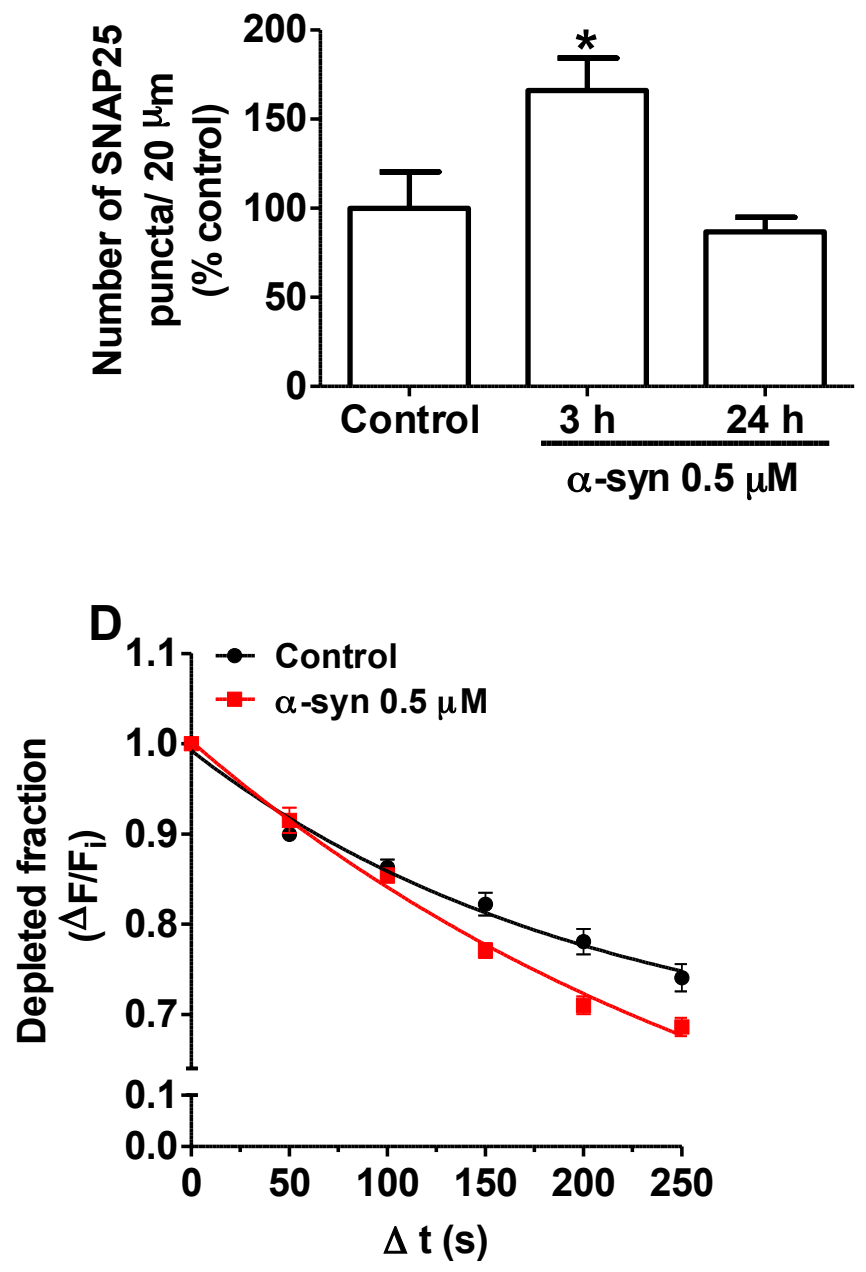


\section{A Control}
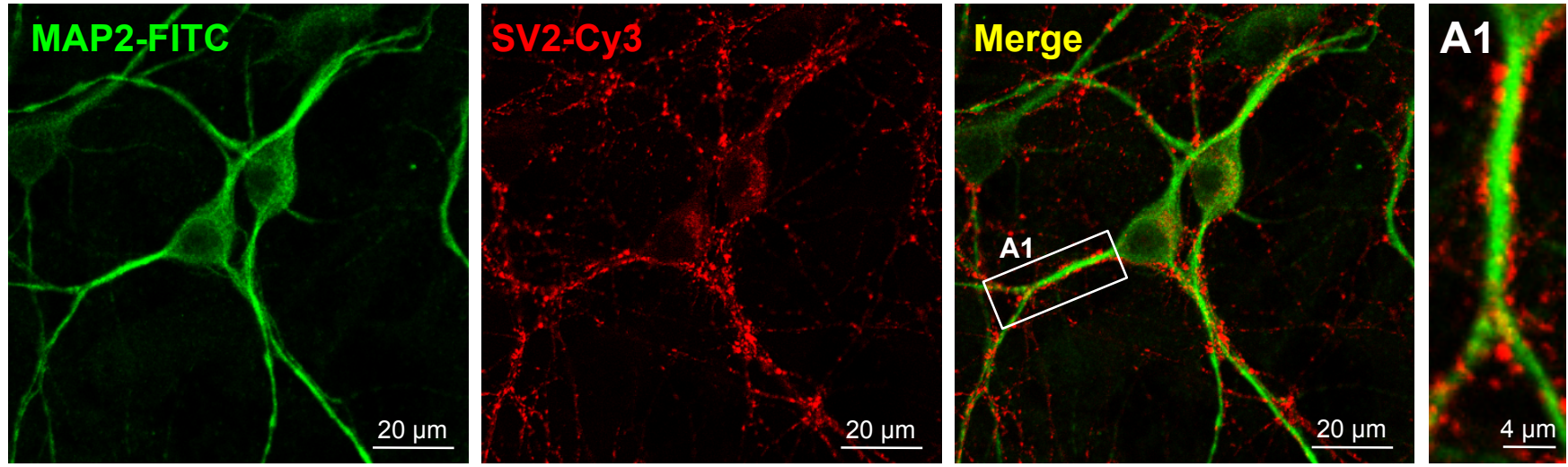

24 h $\alpha-\operatorname{syn} 5 \mu M$
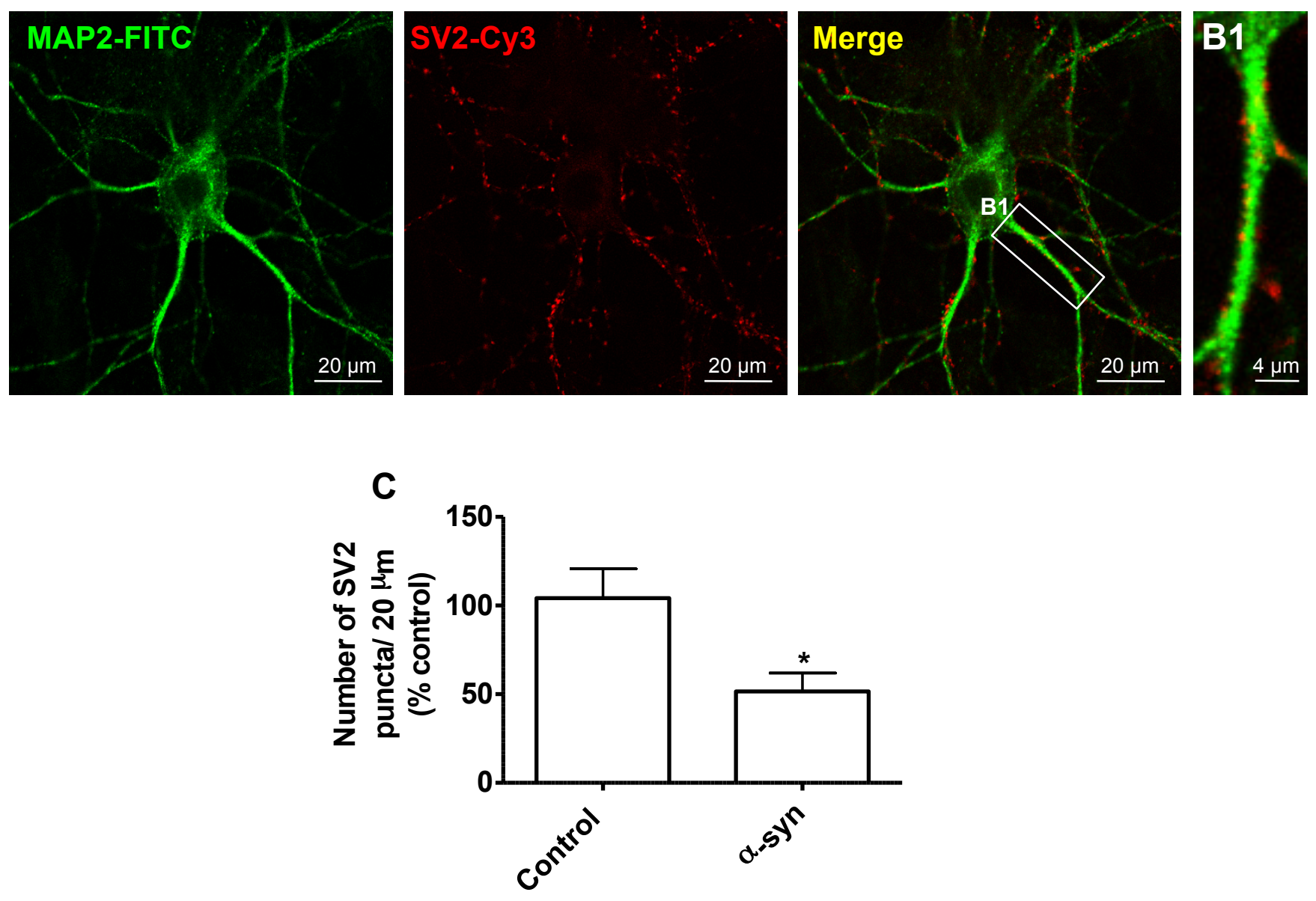

Pacheco et al., Figure 8 


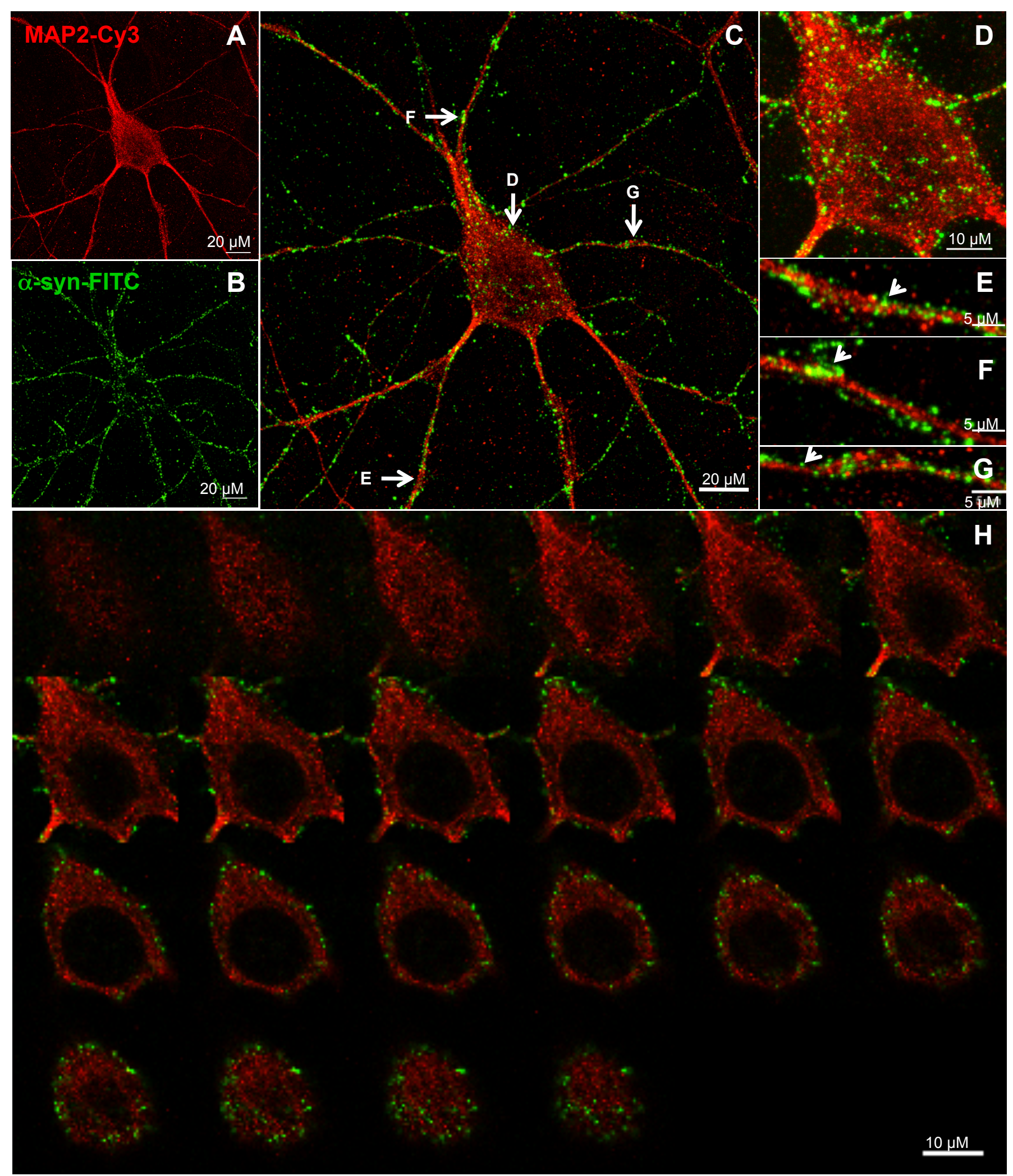

Pacheco et al., Supplementary Figure 1 


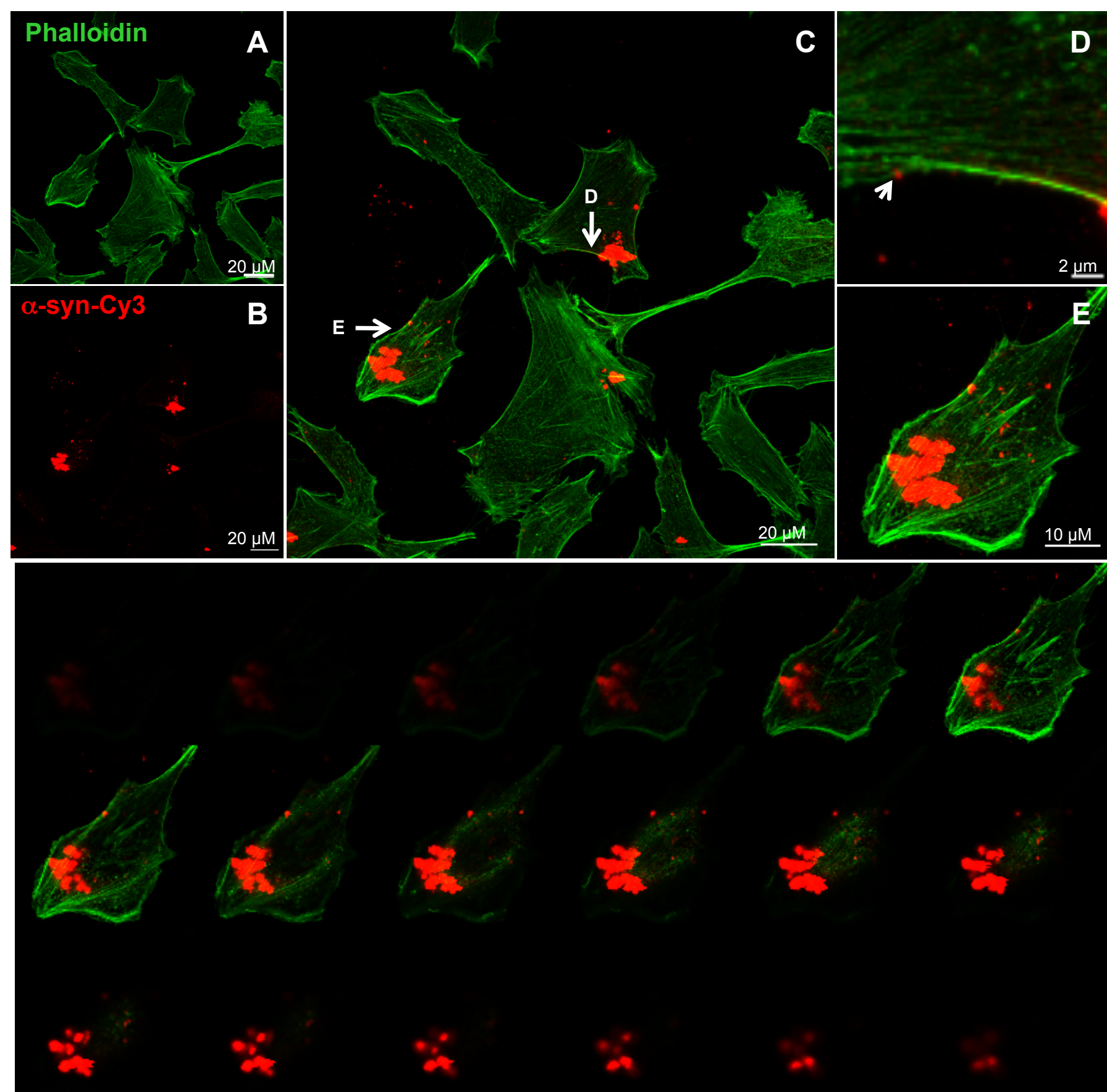

Pacheco et al., Supplementary Figure 2 